\title{
Ageing and transitions: looking back and looking forward
}

\author{
Dorly J. H. Deeg ${ }^{1} \cdot$ Hans-Werner Wahl ${ }^{2} \cdot$ Howard Litwin ${ }^{3}$ \\ Published online: 19 February 2018 \\ c) Springer-Verlag GmbH Germany, part of Springer Nature 2018
}

As researchers on ageing, we are all well aware that ageing comes with transitions. Life goes on as usual, and then comes a point in time that we experience a change: be it in physical fitness, social situation, or mental capacity. Transitions occur during each phase of the life course of an individual, but are definitely prominent in older age. In this editorial, we touch on some of the pertinent research as published in our Journal, and present some reflections related to a transition that affects us personally: we pass on the role of editor to a new generation.

\section{Transition featuring in the European Journal of Ageing}

During the past decade, a good number of articles on transitions in the lives of ageing individuals have been published in the European Journal of Ageing. For example, the prediction of transitions between employment, unemployment, disability or retirement among older workers has been addressed in several articles (Achdut et al. 2014; Dal Bianco et al. 2014). This interest in older workers has emerged relatively recently in ageing research, undoubtedly triggered by the intentions of most western governments to raise the retirement age. A theme that has a longer tradition among gerontologists is transitions in the use of care. Addressing questions such as what triggers the use of informal care versus formal home care, or admission to a care institution, should help target the provision of care to those who need it (Geerts and Van den Bosch 2011; Hallberg and Lagergren

Dorly J. H. Deeg

eja@vumc.nl

1 Department of Epidemiology and Biostatistics, VU University Medical Center, Amsterdam, The Netherlands

2 Department of Psychological Aging Research, University of Heidelberg, Heidelberg, Germany

3 Paul Baerwald School of Social Work and Social Welfare, Hebrew University, Jerusalem, Israel
2009). In particular, insight into transitions through the health and social care system at the end of life is of great importance to support older people in dying with dignity (Aaltonen et al. 2010). In the pathway preceding the use of care are transitions from functioning well to disability, and transitions in healthy lifestyles such as smoking and physical activity (Trias-Llimós et al. 2016; Wong et al. 2008; Zingmark et al. 2016). Predicting and monitoring such transitions is relevant not only for planning health and social care facilities, but also for the design of preventative interventions.

Of course, demographic transitions at the population level have caused an upsurge in interest in research on ageing in general. The ageing of the population leads many countries to reform their social security system. Such macro-level transitions invite comparative studies addressing questions such as how different welfare states approach such reforms and how these affect quality of life, the results of which have potential policy implications (Geerts and Van den Bosch 2011; Motel-Klingebiel et al. 2009). All in all, research on transitions in older age has great societal value. Thanks to the increase in availability of longitudinal datasets across Europe, such research has become increasingly possible.

\section{Our own transition: looking back}

Turning to our own lives, the first two authors of this editorial have recently experienced our own type of transition by stepping down as editors from this Journal as of January 1, 2018. And a bit earlier, as of April 1, 2017, Howie Litwin stepped down. This transition has lead to some introspection. Why did we devote 14 years of our lives (or five in the case of Howie Litwin) to being editors of a scientific journal? What motivated us?

Initially, we were driven by the mission to make European research on ageing more visible, as many of the publications coming from this body of research were scattered in international-very often American-journals. Another important mission was to strengthen the interdisciplinarity of research on ageing. Ageing is an intrinsically interdisciplinary 
process, but although most researchers acknowledge this fact, the publication outlets for interdisciplinary studies were very limited. Founding an interdisciplinary journal provided a new platform for such studies (Deeg and Wahl 2004). After having been involved in research on ageing for many years, each in our own field, we welcomed the opportunity to extend our contribution with a different type of activity than doing our own research.

Over the years, being editors has been a very enjoyable as well as intellectually enriching experience for each of us. Enjoyable, because of the contacts with our authors and reviewers, members of the editorial board, our publisher Springer, and the frequent interaction among us editors. Enriching, because our role allowed us to get to know the larger picture of all kinds of European ageing research and its outcomes. The variety of topics that we learned about through the submitted manuscripts was a source of inspiration, and sometimes even wonder. Although each of us has been doing research on ageing for many years, we were not aware of the breadth and innovativeness of European ageing research. To show the strength of this body of research, we attempted to compile and evaluate the European ageing research area in an article on the occasion of the Journal's 10th volume (Wahl et al. 2013).

In practice, our role boiled down to investing a lot of time in reading articles and writing decision letters. This required paying attention to all the details that constitute the quality of research reports. Although it was sometimes tedious to do this job across all these years, we regarded it as a challenge to take the best editorial decision, even in the case of rejection. It was a great privilege to see publications being 'born' and as the responsible editor being in the position to bring them to a higher quality level. This could be a challenging process, but would certainly lead to a feeling of satisfaction in the end. This was particularly true for publications firstauthored by scholars making their first steps in the world of academic publication. It has been a great pleasure to mentor the next generation of gerontological scholars.

So far, we have highlighted the European aspect of our Journal. At the same time, we had an increasing number of submissions from countries outside Europe. It is great to see all this research effort worldwide. On the other hand, particularly in developing countries, it seemed to us that there is still some way to go to establish a solid ageing research platform. Unfortunately, not many of the submitted papers from developing countries made it to publication. We did not want to apply 'double standards' in evaluating the quality of these submissions. Meanwhile, we feel we are debt in this respect and would like to see more of a coordinated effort to support all these emerging 'ageing plants' in growing to higher quality levels.

Another critical reflection is that as editors, we jumped on the running train of the publication circus. Publishing is still the main criterion for researchers to be able to maintain their position in academia. Despite the critique that this is a one-sided evaluation of research that overshoots its target of achieving quality, the adage 'publish or perish' still flourishes. The result is that too many articles are published with too little real impact. In response, the number of newly launched journals is skyrocketing. Having founded a new journal ourselves makes us in a sense guilty of supporting this practice. Thus, we have to make the best of it by keeping our focus on the interdisciplinarity of research on ageing and by fostering the publication of innovative research.

\section{Our own transition: looking forward}

Now on to the future. To our great satisfaction, we have been able find three excellent scholars to fill the role of editors from now on.

As of April 1, 2017, Marja Aartsen has taken over the social domain. She is a sociologist and research professor at Norwegian Social Research (NOVA), Ageing Research and Housing Studies. She is interested in developments in social functioning of older adults, their relationships with others and how they change with ageing, and how these changes relates to cognitive and mental functioning and physical health.

As of January 1, 2018, Susanne Iwarsson has taken over the health domain. She has a doctoral degree in medical science and is a professor of gerontology and care for older people at the Faculty of Medicine, Lund University, Sweden. Her interests are in environmental gerontology, occupational therapy, rehabilitation, public health, neuroscience, housing, assistive technology. She is the coordinator of the Centre for Ageing and Supportive Environments (CASE) and the Swedish National Graduate School for Competitive Science on Ageing and Health (SWEAH).

Also as of January 1, 2018, Matthias Kliegel has taken over the behavioural domain. He is a professor of psychology at the University of Geneva and chair of Cognitive Ageing. Also, he is the director of the Centre Interfacultaire de Gérontologie et d'études de vulnérabilités (CIGEV). His interests are cognitive development across the lifespan, cognitive and clinical neuroscience of ageing, plasticity of memory and executive functions, the ageing workforce, and health behaviour changes across the lifespan.

Thus, among the three new editors there is broad expertise on ageing, with some overlap in interests. This implies that all three are interdisciplinary scholars by themselves. We are grateful for them taking on the editor role and are confident that the Journal will thrive under their editorship. 


\section{References}

Aaltonen M, Forma L, Rissanen P, Raitanen J, Jylhä M (2010) Transitions in health and social service system at the end of life. Eur $\mathrm{J}$ Ageing 7(2):91-100. https://doi.org/10.1007/s10433-010-0155-3

Achdut L, Tur-Sinai A, Troitsky R (2014) Transitions between states of labor-force participation among older Israelis. Eur J Ageing 12(1):39-49. https://doi.org/10.1007/s10433-014-0328-6

Dal Bianco C, Trevisan E, Weber G (2014) "I want to break free". The role of working conditions on retirement expectations and decisions. Eur J Ageing 12(1):17-28. https://doi.org/10.1007/s1043 3-014-0326-8

Deeg DJH, Wahl H-W (2004) A new ageing research journal: introducing the European Journal of Ageing. Editorial. Eur J Ageing 1(1): $1-5$

Geerts J, Van den Bosch K (2011) Transitions in formal and informal care utilisation amongst older Europeans: the impact of national contexts. Eur J Ageing 9(1):27-37. https://doi.org/10.1007/s1043 3-011-0199-Z

Hallberg D, Lagergren M (2009) Moving in and out of public old age care among the very old in Sweden. Eur J Ageing 6(2):137-145. https://doi.org/10.1007/s10433-009-0111-2
Motel-Klingebiel A, Romeu Gordo L, Betzin J (2009) Welfare states and quality of later life: distributions and predictions in a comparative perspective. Eur J Ageing 6(2):67-78. https://doi. org/10.1007/s10433-009-0112-1

Trias-Llimós S, Muszyńska MM, Cámara AD, Janssen F (2016) Smoking cessation among European older adults: the contributions of marital and employment transitions by gender. Eur J Ageing 14(2):189-198. https://doi.org/10.1007/s10433-016-0401-4

Wahl H-W, Deeg DJH, Litwin H (2013) European ageing research in the social, behavioural and health areas: a multidimensional account. Eur J Ageing 10(4):261-270. https://doi.org/10.1007/ s10433-013-0301-9

Wong R, Ofstedal MB, Yount K, Agree EM (2008) Unhealthy lifestyles among older adults: exploring transitions in Mexico and the US. Eur J Ageing 5(4):311-326

Zingmark M, Nilsson I, Norström F, Sahlén KG, Lindholm L (2016) Cost effectiveness of an intervention focused on reducing bathing disability. Eur J Ageing 14(3):233-241. https://doi.org/10.1007/ s10433-016-0404-1 